\title{
Seasonal, Age \& Gender Variation of Guillain Barre Syndrome in a Tertiary Referral Center in India
}

\author{
Geetanjali Sharma $^{1 *}$, Sushma Sood ${ }^{1}$, Sudhir Sharma ${ }^{2}$ \\ ${ }^{1}$ Department of Physiology, University of Health Sciences, Rohtak, India; ${ }^{2}$ Department of Medicine, University of Health Sciences, \\ Rohtak, India. \\ Email: *drgeeta1212@yahoo.com
}

Received December $16^{\text {th }}$, 2012; revised January 20 $0^{\text {th }}, 2013$; accepted February $3^{\text {rd }}, 2013$

\begin{abstract}
Background: Seasonal variation \& gender preponderance have not been adequately studied in Guillain Barre Syndrome (GBS). University of Health Sciences, Rohtak is the tertiary referral facility for a large part of North West India. We conducted a prospective study to investigate differences in GBS incidence between males and females \& across different seasons of the year. Methods: 65 clinically diagnosed GBS patients, aged 5 - 70 years, referred for nerve conduction, F-wave \& EMG studies for 3 years. Results: $64.61 \%$ were males while $35.38 \%$ were females. Maximum patients were in the age group 5 - 20 years (46.15\%). The highest incidence of GBS (41.53\%) were seen in the summer months; 19 (29.23\%) in the spring season, $11(16.92 \%)$ in winter season and $8(12.30 \%)$ in rainy season. 5 patients had diarrhoea while 12 patients had flu like syndrome 1 - 2 weeks before the onset of GBS. Conclusion: The peak seasonal clustering noted by us in the summer months was consistent significantly with other Asian studies. The age and sex distribution of GBS in our series, which showed children \& minor preponderance with peak incidence in 5 - 20 years age followed by another in the age group 21 - 40 years, is different from most studies which report a second peak after 50 years of age.
\end{abstract}

Keywords: EMG; Epidemiology; Guillain-Barre Syndrome; Neuroepidemiology

\section{Introduction}

GB syndrome is an auto-immune mediated demyelinating polyradiculo-neuropathy. Males \& females are equally at risk. Clinical features include progressive, symmetrical ascending muscle weakness of more than two limbs, areflexia with or without sensory, autonomic and brainstem abnormalities. Weakness prominent in leg muscles as compared to arms, absence of fever at the onset of neural symptoms. Cranial nerve involvement may affect airway and facial muscles, eye movements and swallowing [1]. It usually presents with numbness and tingling in the feet [2].

In 1949, Haymaker \& Kernohan reported the histopathological features of 50 fatal cases of GB syndrome. The earliest features were oedema of proximal nerves followed by degeneration of myelin sheath within the 1st week of illness [2].

Electro-diagnosis plays an important role in early detection and characterization of inflammatory demyelinating polyradiculopathies [3].

Nerve conduction and F wave studies have been conducted from all over the world and the results are well

*Corresponding author. documented. However, studies reporting seasonal variation with respect to this common syndrome are far and few. Only a couple of studies from India have specifically been carried out on this account, that too with varying results.

McGrogan et al. conducted a retrospective study from available literature on worldwide incidence of GBS. Most of the studies included in this review were from Europe and North America. For other parts of the world, very few studies were found, and therefore it was difficult to comment on any geographical trends [4].

Seasonal variation in incidence has been reported in Western and Pakistan based studies, the latter being very encouraging as it neighbors India. A few studies have found male preponderance while others have found no gender differentiation. The above suggests heterogeneity between epidemiology and electro-physiological pattern of GBS [5]. Guillain Barre syndrome occurs throughout the year long sporadically with peaks reported at different periods. The same pattern has been reported in the studies by Sharma et al. and Kannan et al. [6,7]. The present paper is an attempt to comment on the seasonal peaking and gender preponderance of clinically diagnosed patients of Guillain Barre Syndrome in a tertiary institute serving 
as a referring base for a major region of North India.

\section{Methods}

The present study was carried as a side by side profile on patients referred to our department from the out-patient department of Medicine to facilitate early confirmation of clinically diagnosed cases of GB syndrome in the 1st week of illness for nerve conduction. The study was conducted on 65 subjects (42 males \& 23 females) between the age group of 5 - 70 years. The criteria for clinical diagnosis of GBS were rapidly progressive limb weakness with or without distal limb paresthesias and reduced deep tendon reflexes. All patients selected for this profile fulfilled the Dutch Guillan Barre study group criteria for diagnosis of GBS [8]. The detailed case history of from each patient or relative was taken and analysed cumulatively.

\section{Results}

\subsection{Demographics}

Of the 65 patients who were assessed, 42 (64.61\%) were males while 23 were females (35.38\%), the sex ratio being 1.82:1 (Figure 1). The age of the patients ranged from 5 - 70 years with a mean age of 37.5 years (Table 1). The peak incidence was seen in the group of 5 - 20 years ( $\mathrm{n}=30,46.15 \%)$, followed by the age group 21 40 years $(n=18,27.69 \%)$, the age group $41-60(n=11$, $16.92 \%)$ while only $6(9.23 \%)$ patients were aged above 60 years (Table $\mathbf{1}$ ).

\subsection{Seasonal Variation}

The highest incidence of GBS ( $\mathrm{n}=27,41.53 \%$ ) were seen in the summer months from May to July; there were 19 (29.23\%) cases in the spring season from February to April, 11 (16.92\%) in the winter season from November to January and $8(12.30 \%)$ in the rainy season from August to October (Figure 2). Though the disease occurred sporadically throughout the year, month wise incidence was topped by May and July with 10 patients each

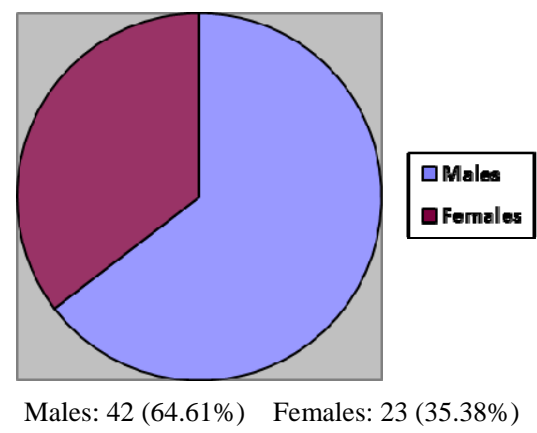

Figure 1. Pie chart depicting male to female ratio of GBS cases.
Table 1. Age and sex distribution in cases of GBS.

\begin{tabular}{|c|c|c|c|}
\hline \multirow{2}{*}{ Age } & \multicolumn{2}{|c|}{ Sex } & \multirow{2}{*}{ Total \% } \\
\hline & Male & Females & \\
\hline $0-20$ Years & 20 & 10 & $30(46.15)$ \\
\hline 21 - 40 Years & 10 & 8 & $18(27.69)$ \\
\hline 41 - 60 Years & 8 & 3 & $11(16.92)$ \\
\hline \multirow[t]{2}{*}{$>60$ Years } & 4 & 2 & $6(9.23)$ \\
\hline & 42 & 23 & 65 (100) \\
\hline
\end{tabular}

Male to female ratio: 1.82:1.

(15.38\%), followed by February (9 patients, 13.84\%) and June (7 patients, $10.76 \%$ ). The least number of cases were seen in October and November (1 each, 1.53\%). As per the detailed history of each case, 5 patients (7.69\%) had diarrhoea while 12 (18.46\%) patients had flu like syndrome 1 - 2 weeks before the onset of GBS.

\section{Conclusions}

We did demographical profiling of 65 patients who reported for nerve conduction studies from the out-patient department with clinical diagnosis of GBS over a period of three years from 2010 to 2012. Although the disease occurred throughout the year in all seasons, the highest incidence was seen in the summer months of May to July. Another peak was seen in the spring months of February to April. Month wise peaks were seen in May and July; another peak was seen in February. In the first of the Indian reports by Sharma et al., maximum incidence was seen spring and summer, with major clustering seen in spring followed by summer [6]. In contrast, our study reports maximum case clustering in summer months, followed by spring, though overall peaking is comparable in both studies considering the total incidence from February to July. Both these studies are more or less from the same geographical area of North India, both facilities being tertiary centres. The other study was from south India, where the researchers reported a peak incidence from July to September [7]. This finding is expectedly in contrast to our results as there is a stark difference between the geographical and climatic conditions in both studies (Table 2).

A study by Akbayram et al. in Turkey revealed a seasonal predominance in summer and spring, accounting for $41.6 \%$ and $22.2 \%$ respectively of the episodes, which is similar to our findings [9]. Peak summer clustering has also been reported by Hughes et al. in a Northern China based study [10]. Zaheer et al. in a Pakistani study have also reported peak summer incidence of GBS (April to September) i.e. 64\% [5]. A study based in Northern China by Ho et al. also found summer predominance in 


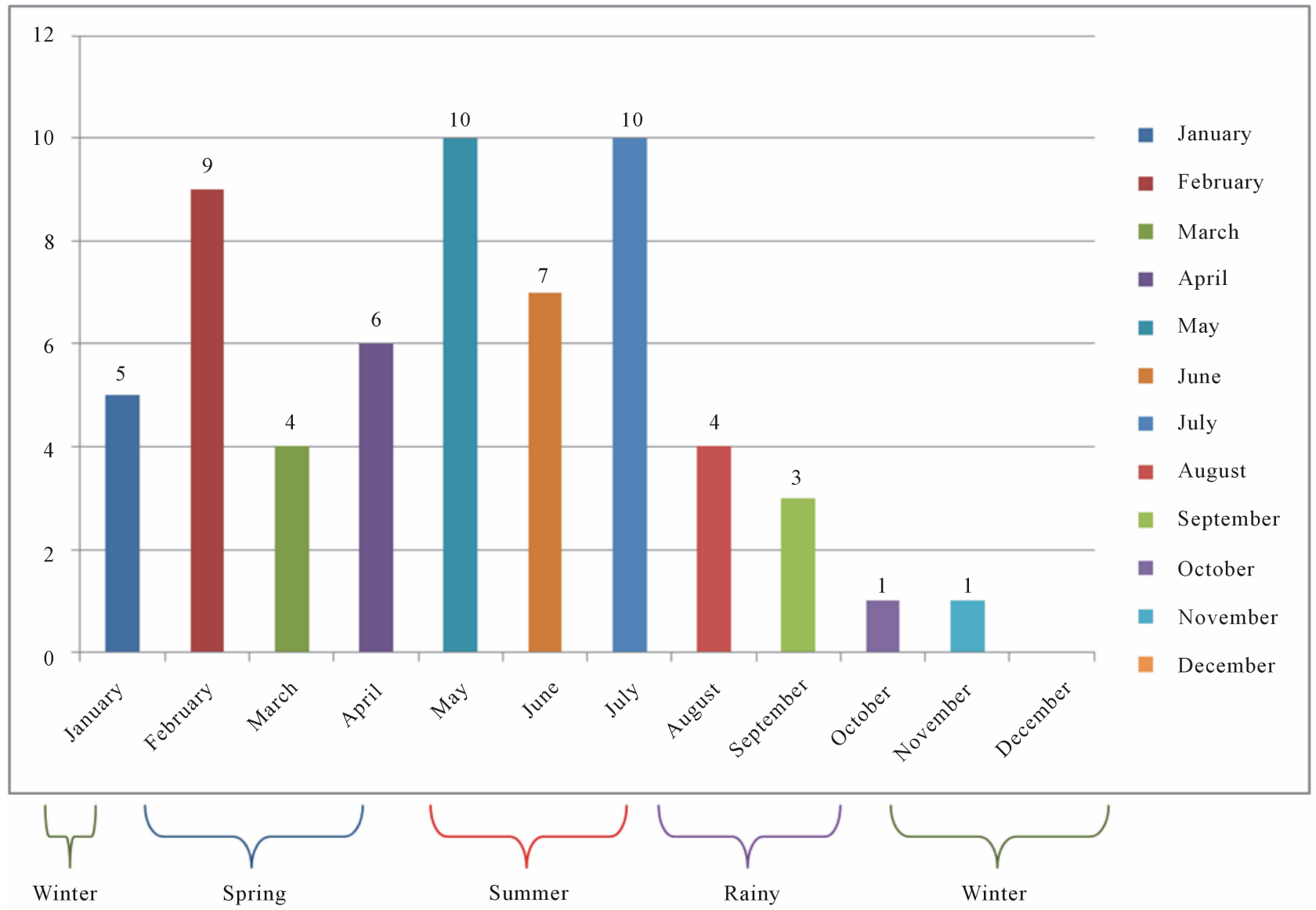

Figure 2. Seasonal incidence of GBS.

Table 2. Table depicting seasonal variation comparison in various study groups.

\begin{tabular}{|c|c|c|c|c|c|}
\hline Study groups & Summer season & & Spring season & Rainy/fall season & Winter season \\
\hline Present study ${ }^{*}$ (India) & 27 (41.53\%) & & $19(29.23 \%)$ & $8(12.30 \%)$ & $11(16.92 \%)$ \\
\hline Sharma et al. ${ }^{*}$ (India) & $11(22 \%)$ & & $20(40 \%)$ & \multicolumn{2}{|c|}{19 (38\%) } \\
\hline Akbayram et al." (Iran) & $10(40 \%)$ & & $8(32 \%)$ & $5(20 \%)$ & $2(8 \%)$ \\
\hline Zaheer et al. ${ }^{*}$ (Pak) & $16(64 \%)$ & & & $9(26.5 \%)$ & \\
\hline Yaqoob et al. ${ }^{*}$ (Pak) & $3(8.82 \%)$ & & $11(32.4 \%)$ & $11(32.4 \%)$ & $9(26.5 \%)$ \\
\hline Coe et al. ${ }^{*}$ (Korea) & $54(40.90 \%$ & & $25(18.93 \%)$ & 35 (26.51\%); & $15(11.36 \%)$ \\
\hline Haghighi et al. ${ }^{*}$ (Iran) & $90(23.13 \%)$ & & $113(29.04 \%)$ & $71(18.25 \%)$ & $115(29.56 \%)$ \\
\hline Lyu et al. (Taiwan) & & & $44 / 47 \%$ & & \\
\hline Arami et al.* (Saudi Arabia) & $14(18 \%)$ & & $15(21 \%)$ & $14(18 \%)$ & $32(43 \%)$ \\
\hline Louie et al. ${ }^{+}$(USA) & $(22 \%)$ & & $(20 \%)$ & $(27 \%)$ & $(31 \%)$ \\
\hline Sivadon-Tardy et al. (France) & & & & & $60 \%$ \\
\hline Rocha et al. ${ }^{+}$(Brazil) & & $62.1 \%$ & & & \\
\hline Larson et al. ${ }^{+}$(Norway) & & & & & Max \\
\hline Rebecca Prevots et al. ${ }^{+}$(USA) & & & No seas & tion noted & \\
\hline
\end{tabular}

*-Asian studies; ${ }^{+}$-Western studies. 
Table 3. Table depicting age group comparison in various study groups.

\begin{tabular}{|c|c|c|c|c|}
\hline \multirow{2}{*}{ Study groups } & \multicolumn{4}{|c|}{ Age groups } \\
\hline & $0-20$ & $21-40$ & $41-60$ & $>60$ \\
\hline Present study ${ }^{*}$ & 30 (46.15\%) & 18 (27.69) & $11(16.92 \%)$ & $6(9.23 \%)$ \\
\hline Sharma et al. & & $44 \%$ & & \\
\hline Zaheer et al. ${ }^{*}$ & \multicolumn{2}{|c|}{$80.93 \%$ (0 - 30 yrs) } & & \\
\hline Yakoob et al. ${ }^{*}$ & $29.4 \%$ & & & \\
\hline Louie et al. ${ }^{+}$(USA) & 8 (15.68\%) & $13(25.49 \%)$ & $12(23.52 \%)$ & 18 (35.29\%) \\
\hline
\end{tabular}

*-Asian studies; ${ }^{+}$-Western studies.

GBS incidence [11]. Similar findings have been reported by Coe in a Korean study with a second peak in the fall [12]. In a study on the chronological variation of GBS in north west of Iran by Samad et al., a peak occurrence of GBS has been reported in spring and autumn, with most cases seen in May (13.6\%) [13].

Our study also reports maximum cases in May and July. Islam et al. in a study on childhood GBS from neighbouring Bangladesh have reported maximum cases in the month of May and least in February [14]. In another Iran based study by Haghighi et al., the maximal incidence of GBS was reported between the months of February to June [15]. Lyu et al. have reported the peak GBS incidence from March to May in a Taiwanese study [16].

Conversely, peak clustering of GBS in the winter months has been reported from studies done primarily from the Western Hemisphere [17-23] and a study in Iran [24] while other studies from the same regions have seen no secular seasonal variation in occurrence of GBS [2529].

Taking gender into consideration (Table 3), our study showed very significant male preponderance with 42 (64.61\%) males and 23 were females (35.38\%), the sex ratio being 1.82:1. This finding is in consistence with all studies on GBS. However, in our series, we found major incidence in the age group of $5-20$ years $(n=30$, $46.15 \%$ ), which was in variance with most studies in which the maximum number of cases have been associated with $>40$ years of age. Only 11 cases out of 65 were in the age group of 41 - 60 (16.92\%) while only 6 (9.23\%) patients were aged above 60 years. In comparison to our findings, the first Indian study by Sharma et al. reported $44 \%$ patients in the 20 - 40 years age group [6] while Kannan et al. had studied the pediatric age group only [7]. Pakistani studies by Zaheer et al. (80.93\% patients in age group 11 - 30 years) and Yakoob et al. (29.4\% patients less than 18 years of age) correlate well with our results [5,31]. Other Asian reports include China where Cheng et al. [32] inform highest GBS incidence in the youngest age-group and the incidence among the elderly being remarkably lower than those reported from other populations in Western countries (which is consistent with our findings); and Taiwan (highest frequency i.e. 21\% of all patients occurring in children under the age of 10 years) $[16,30]$.

In this study series, 5 patients (7.69\%) had diarrhoea while $12(18.46 \%)$ patients had flu like syndrome 1 - 2 weeks before the onset of GBS. This finding matches well with the observations of Zaheer et al. from Pakistan that some sort of relationship exists in Asian countries between seasonal peaks of GBS with widespread epidemics of summer gastroenteritis and winter flu like syndromes [5]. In our region, gastroenteritis outbreaks in warmer months can be linked to summer clustering of GBS and lesser relationship of it with winter flu-like syndromes.

To conclude, a similarity to a substantial level exists between seasonal and gender based incidence of GBS in the Asian region. More cases are reported in the warmer months of the year as compared to the winter season. Further, there is increased incidence in the younger age group as compared to the elder age predominance seen in the western hemisphere; the syndrome being more prevalent in males.

\section{Acknowledgements}

The authors would like to acknowledge Mr. Randhir Singh, Senior Laboratory Technician, Department of Physiology at University of Health Sciences, Rohtak for his untiring help during electro-physiological tests conducted on the patients.

\section{REFERENCES}

[1] S. L. Hauser and A. K. Asbury, "Guillain-Barre Syndrome \& Other Immune-Mediated Neuropathies,” In: 16th Edition, Harrison's Principles of Internal Medicine, McGraw Hill, 2009, pp. 2667-2671.

[2] A. A. Amato, "Guillain Barre Syndrome \& Related Disorders,” Revista Mexicana de Neurociencia, Vol. 6, No. 5, 2005, pp. 455-469. 
[3] P. H. Gordon and A. J. Wilbourn, "Early Electrodiagnostic Findings in Guillain Barre Syndrome," Archives of Neurology, Vol. 58, No. 6, 2001, pp. 913-917.

[4] A. McGrogan, G. C. Madle, H. E. Seaman and C. S. de Vries, "The Epidemiology of Guillain-Barré Syndrome Worldwide-A Systematic Literature Review,” Neuroepidemiology, Vol. 32, No. 2, 2009, pp. 150-163. doi:10.1159/000184748

[5] M. Zaheer, M. Naeem and M. Nasrullah, "Seasonal Variation and Sex Distribution in Patients with Guillain-Barre Syndrome,” Pakistan Journal of Neurological Sciences, Vol. 3, No. 1, 2008, pp. 6-8.

[6] A. Sharma, V. Lal, M. Modi, C. Vaishnavi and S. Prabhakar, "Campylobacter jejuni Infection in Guillain-Barré Syndrome: A Prospective Case Control Study in a Tertiary Care Hospital,” Neurology India, Vol. 59, No. 5, 2011, pp. 717-721. doi:10.4103/0028-3886.86547

[7] M. A. Kannan, R. Kishore, S. A. Jabeen, K. R. Mridula, P. Rao and R. Borgohain, "Clinical, Electrophysiological Subtypes and Antiganglioside Antibodies in Childhood Guillain-Barré Syndrome,” Neurology India, Vol. 59, No. 5, 2011, pp. 727-732. doi:10.4103/0028-3886.86549

[8] J. Meustec, F. G. A. Van Der Meche and the Dutch Guillain Barre Study Group, "Electrodiagnostic Criteria for Polyneuropathy and Demyelination: Application in 135 Patients with Guillain Barre Syndrome,” Journal of Neurology, Neurosurgery \& Psychiatry, Vol. 59, No. 5, 1995, pp. 482-486. doi:10.1136/jnnp.59.5.482

[9] S. Akbayram, M. Dogan, C. Akgün, E. Peker, R. Sayin and F. Aktar, "Clinical Features and Prognosis with Guillain-Barré Syndrome,” Annals of Indian Academy of Neurology, Vol. 14, No. 2, 2011, pp. 98-102. doi:10.4103/0972-2327.82793

[10] R. A. Hughes and J. H. Rees, "Clinical and Epidemiological Features of Guillain Barre Syndrome,” The Journal of Infectious Diseases, Vol. 176, No. 2, 1997, pp. S92S98. doi:10.1086/513793

[11] T. W. Ho, B. Mishu, C. Y. Li, C. Y. Gao, D. R. Cornblath, J. W. Griffin, A. K. Asbury, M. J. Blaser and G. M. McKhann, "Guillain-Barré Syndrome in Northern China. Relationship to Campylobacter jejuni Infection and AntiGlycolipid Antibodies,” Brain, Vol. 118, No. 3, 1995, pp. 597-605. doi:10.1093/brain/118.3.597

[12] C. J. Coe, "Guillain Barre Syndrome in Korean Children,” Yonsei Medical Journal, Vol. 30, No. 1, 1989, pp. 81-87.

[13] S. V. Samad, R. M. Leila, H. Samaneh, D. Ghazaleh and H. Paria, "The Chronological Variation of Guillain Barre Syndrome (GBS) in North West of Iran,” Journal of Medical Sciences Research, Vol. 1, No. 3, 2011, pp. 19-24.

[14] Z. Islam, B. C. Jacobs, M. B. Islam, Q. D. Mohammad, S. Diorditsa and H. P. Endtz, "High Incidence of GuillainBarré Syndrome in Children, Bangladesh,” Emerging Infectious Diseases, 2011. doi:10.3201/eid1707.101999

[15] A. B. Haghighi, M. A. Banihashemi, N. Zamiri, B. Sabayan, S. T. Heydari and A. Safari, "Seasonal Variation of Guillain-Barré Syndrome Admission in a Large Tertiary Referral Center in Southern Iran: A 10 Year Analysis,”
Acta Neurologica Taiwanica, Vol. 21, 2012, pp. 60-6321.

[16] R. K. Lyu, L. M. Tang, S. Y. Cheng, W. C. Hsu and S. T. Chen, "Guillain-Barré Syndrome in Taiwan: A Clinical Study of 167 Patients,” Journal of Neurology, Neurosurgery \& Psychiatry, Vol. 63, No. 4, 1997, pp. 494-500. doi:10.1136/jnnp.63.4.494

[17] R. Van Koningsveld, R. Rico, I. Gerstenbluth, P. I. M. Schmitz, C. W. Ang and I. S. J. Merkies, "GastroenteritisAssociated Guillain-Barré Syndrome on the Caribbean Island Curaçao,” Neurology, Vol. 56, No. 11, 2001, pp. 1467-1472. doi:10.1212/WNL.56.11.1467

[18] K. Radhakrishnan, M. A. El-Mangoush and S. E. Gerryo, "Descriptive Epidemiology of Selected Neuromuscular Disorders in Benghazi, Libya," Acta Neurologica Scandinavica, Vol. 75, No. 2, 1987, pp. 95-100. doi:10.1111/j.1600-0404.1987.tb07901.x

[19] S. J. Winner and J. Grimley Evans, "Age-Specific Incidence of Guillain-Barré Syndrome in Oxfordshire," $O x$ ford Journals of Medicine, Vol. 77, No. 3, 1990, pp. 12971304. doi:10.1093/qjmed/77.3.1297

[20] S. Congia, M. Melis and M. A. Carboni, "Epidemiologic and Clinical Features of the Guillain-Barre Syndrome in Sardinia in the 1961-1980 Period,” Acta Neurologica (Napoli), Vol. 11, No. 1, 1989, pp. 15-20.

[21] J. P. Larson, G. Kvale and H. Nyland, "Epidemiology of the Guillain-Barre Syndrome in the County of Hordaland, Western Norway,” Acta Neurologica Scandinavica, Vol. 71, No. 1, 1985, pp. 43-47. doi:10.1111/j.1600-0404.1985.tb03165.x

[22] V. Sivadon-Tardy, D. Orlikowski, F. Rozenberg, C. Caudie, T. Sharshar, P. Lebon, et al., "Guillain-Barré Syndrome, Greater Paris Area,” Emerging Infectious Diseases, Vol. 12, No. 6, 2006. doi:10.3201/eid1206.051369

[23] M. Louie, J. M. Gilchrist and C. Woodland, "Guillain Barre Syndrome: A 5 Year Rhode Island Hospital Experience,” Rhode Island Medicine, Vol. 77, 1994, pp. 135140. http://med.brown.edu/neurology/articles/ml13594.pdf

[24] M. A. Arami, M. Yazdchi and R. Khandaghi, "Epidemiology and Characteristics of Guillain Barre Syndrome in the Northwest of Iran," Annals of Saudi Medicine, Vol. 26, No. 1, 2006, pp. 22-27.

[25] E. Storey, M. Cook, R. Peppard, H. Newton-John and E. Byrne, "Guillain-Barre Syndrome and Related Conditions in Victorian Teaching Hospitals 1980-1984,” Australian and New Zealand Journal of Medicine, Vol. 19, No. 6, 1989, pp. 687-693.

doi:10.1111/j.1445-5994.1989.tb00335.x

[26] Z. Paolino, V. Govoni, M. R. Tola, I. Casetta and E. Granieri, "Incidence of the Guillain-Barre Syndrome in Ferrara, Northern Italy, 1981-1987," Neuroepidemiology, Vol. 10, No. 3, 1991, pp. 105-111. doi:10.1159/000110254

[27] V. Govoni, E. Granieri, M. R. Tola, I. Casetta, P. Ruppi and L. Vaghi, "The Frequency of Clinical Variants of Guillain-Barre Syndrome in Ferrara, Italy,” Journal of Neurology, Vol. 246, No. 11, 1999, pp. 1010-1014. doi:10.1007/s004150050505 
[28] M. J. Sedano, J. Calleja, E. Canga and J. Berciano, “Guillain-Barre Syndrome in Cantabria, Spain: An Epidemiological and Clinical Study,” Acta Neurologica Scandinavica, Vol. 89, No. 4, 1994, pp. 287-292. doi:10.1111/j.1600-0404.1994.tb01682.x

[29] E. Dias-Tosta and C. S. Kuckelhaus, "Guillain Barré Syndrome in a Population Less than 15 Years Old in Brazil," Arquivos de Neuro-Psiquiatria, Vol. 60, No. 2B, 2002, pp. 367-373. doi:10.1590/S0004-282X2002000300005

[30] D. Rebecca Prevots and R. W. Sutter, "Assessment of Guillain-Barre Syndrome Mortality and Morbidity in the United States: Implications for Acute Flaccid Paralysis Surveillance," The Journal of Infectious Diseases, Vol.
175, No. 1, 1997, pp. S151-S155

doi:10.1093/infdis/175.Supplement 1.S151

[31] M. Y. Yakoob, A. Rahman, B. Jamil and N. A. Syed, "Characteristics of Patients with Guillain Barre Syndrome at a Tertiary Care Centre in Pakistan, 1995-2003,” Journal of the Pakistan Medical Association, Vol. 55, No. 11, 2005, pp. 493-496.

[32] Q. Cheng, D. S. Wang, G. X. Jiang, H. Han, Y. Zhang, W. Z. Wang and S. Fredrikson, "Distinct Pattern of AgeSpecific Incidence of Guillain-Barré Syndrome in Harbin, China,” Journal of Neurology, Vol. 249, No. 1, 2002, pp. 25-32. doi:10.1007/PL00007844 